\title{
Gastroesophageal reflux symptoms in Turkish people: a positive correlation with abdominal obesity in women
}

\author{
Sergul Karayaka', Banu Mesci², Aytekin Oguz ${ }^{2}$, Gonca Tamer ${ }^{3}$ \\ ${ }^{1}$ Department of Family Medicine, Istanbul Medeniyet University, Goztepe Training and Research Hospital, Istanbul, Turkey; \\ ${ }^{2}$ Department of $2^{\text {nd }}$ Internal Medicine Clinic, Istanbul Medeniyet University, Goztepe Training and Research Hospital, \\ Istanbul, Turkey; \\ ${ }^{3}$ Department of Endocrinology, Istanbul Medeniyet University, Goztepe Training and Research Hospital, Istanbul, Turkey
}

\begin{abstract}
OBJECTIVE: Metabolic syndrome (MetS) is increasing around the world due to abdominal obesity with altered eating habits and decreased physical activity. The aim of this study was to determine the risk factors for gastroesophagial reflux disease (GERD) symptoms and the prevalence of GERD in patients with MetS.

METHODS: Five hundred patients (MetS, $n=300$ and the control group, $n=200$ ) were enrolled in the study. A detailed questionnaire reflux symptoms and behavioral habits was performed.

RESULTS: Sixty percent of the subjects were with MetS. GERD rate was significantly higher in the group with MetS compared to subjects without MetS ( $50.7 \%$ vs $26 \%$ ). Women were more likely to have GERD in both groups (62.6\% of women and $28.6 \%$ of men in the MetS group while corresponding rates were $37 \%$ vs $16.7 \%$ in the control group). Waist circumferences were found to be higher in female MetS patients with GERD.
\end{abstract}

CONCLUSION: GERD is present approximately in every one of the two patients with MetS. Every patient who has MetS should be evaluated in terms of GERD symptoms.

Key words: Abdominal obesity; gastroesophageal reflux; metabolic syndrome; obesity; Turkish population.

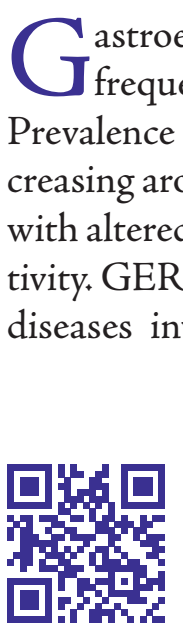

Received: October 27, 2014 Accepted: December 07, 2014 Online: January 24, 2015

Correspondence: Dr. Banu MESCI. Istanbul Medeniyet Universitesi, Goztepe Egitim ve Arastirma Hastanesi, 2. Dahiliye Klinigi, Istanbul, Turkey. 
TABLE 1. Demographic data of the patients

\begin{tabular}{lccc} 
& MetS group & Control group & \\
\cline { 1 - 3 } Female & $67.9 \%$ & $50.7 \%$ & \\
\cline { 2 - 3 } & Mean \pm SD & Mean \pm SD & $p$ \\
\hline Age & $52.83 \pm 9.85$ & $51.86 \pm 12.71$ & 0.21 \\
BMI $\left(\mathrm{kg} / \mathrm{m}^{2}\right)$ & $32.43 \pm 4.88$ & $23.42 \pm 2.69$ & 0.001 \\
Waist circumference $(\mathrm{cm})$ & $107.89 \pm 10.45$ & $82.86 \pm 7.88$ & 0.001
\end{tabular}

The aim of the present study was to determine the risk factors and the prevalence of GERD symptoms in patients with MetS.

\section{MATERIALS AND METHODS}

The study was conducted in Goztepe Training and Research Hospital outpatient clinics between 2008 and 2009. Five hundred patients (MetS, n=300 and the control group, $n=200$ ) were enrolled in the study. MetS was identified according to the criteria of The International Diabetes Federation (IDF) [4]. Exclusion criteria were pregnancy, hormone replacement therapy, history of gastric surgery. The study protocol was designed in accordance with the relevant criteria of Helsinki Declaration and was approved by the local ethics committee of Goztepe Training and Research Hospital. Subjects provided their written informed consent. Demographic and clinic data were recorded. Their physical examina-

TABLE2. Reflux prevalence in groups

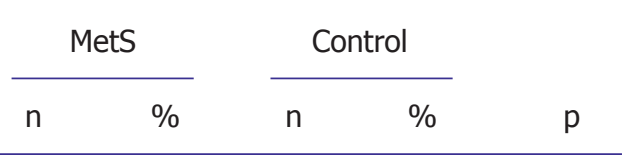

Reflux

$\begin{array}{cccccc}+ & 152 & 50.7 & 52 & 26.0 & 0.001^{* *} \\ - & 148 & 49.3 & 148 & 74.0 & \end{array}$

tion was performed; height, weight, and waist circumference measurements were performed. Body mass index (BMI) was calculated by dividing weight in $\mathrm{kg}$ by height in $\mathrm{m}^{2}$. Systolic and diastolic blood pressures (BP) were recorded. Waist circumferences were measured at the plane between anterior superior iliac spines and lower costal margins at the narrowest part of the waistline while patients were standing during slight expiration. Waist circumferences $>80 \mathrm{~cm}$ for women and $>94 \mathrm{~cm}$ for men were accepted as abdominal obesity according to IDF. A detailed questionnaire asking reflux symptoms and behavioral habits was performed. GERD symptoms were defined as a 'yes' response to all three of the following components: the presence or absence of heartburn, indigestion or pain in your stomach, a tender point palpated on the upper abdomen and relief with antacid. Related risk factors such as tobacco smoking, alcohol intake, eating habits, physical activity and the sleeping position were investigated in both groups.

\section{Statistical analysis}

NCSS (Number Cruncher Statistical System), 2007\&2008 Statistical Software PASS (Utah, USA) program were used. Student's t test was used for comparison of descriptive statistical data (mean, standard deviation, frequency) as well as quantitative parameters showing normal distribution of data between groups. The chi-square test was used to compare qualitative data. 
TABLE 3. Reflux prevalence in groups according to the gender of the patients

\begin{tabular}{|c|c|c|c|c|c|c|}
\hline & \multirow{2}{*}{ Reflux } & \multicolumn{2}{|c|}{ Female } & \multicolumn{2}{|c|}{ Male } & \multirow{2}{*}{$p$} \\
\hline & & $\mathrm{n}$ & $\%$ & $\mathrm{n}$ & $\%$ & \\
\hline \multicolumn{7}{|l|}{ MetS } \\
\hline & + & 122 & 62.6 & 30 & 28.6 & \multirow{2}{*}{$0.001^{* *}$} \\
\hline & - & 73 & 37.4 & 75 & 71.4 & \\
\hline \multicolumn{7}{|l|}{ Control group } \\
\hline & + & 34 & 37.0 & 18 & 16.7 & \multirow{2}{*}{$0.001^{* *}$} \\
\hline & - & 58 & 63.0 & 90 & 83.3 & \\
\hline
\end{tabular}

TABLE 4. Reflux prevalence according to waist circumference

\begin{tabular}{|c|c|c|c|c|c|}
\hline & \multicolumn{4}{|c|}{ Reflux } & \multirow{3}{*}{$\mathrm{p}$} \\
\hline & \multicolumn{2}{|c|}{+} & \multicolumn{2}{|c|}{-} & \\
\hline & $\mathrm{n}$ & $\%$ & $\mathrm{n}$ & $\%$ & \\
\hline \multicolumn{6}{|l|}{ Waist circumference (women) } \\
\hline$<80 \mathrm{~cm}$ (31.5 in) & 34 & 21.8 & 58 & 44.3 & \\
\hline $80-88 \mathrm{~cm}(31.5-34.6 \mathrm{in})$ & 5 & 3.2 & 0 & 0 & $0.001^{* *}$ \\
\hline$>88 \mathrm{~cm}(34.6 \mathrm{in})$ & 117 & 75.0 & 73 & 55.7 & \\
\hline \multicolumn{6}{|l|}{ Waist circumference (men) } \\
\hline$<94 \mathrm{~cm}$ (37 in) & 18 & 37.5 & 90 & 54.5 & \\
\hline $94-102 \mathrm{~cm}(37-40.2)$ & 7 & 14.6 & 21 & 12.7 & 0.100 \\
\hline$>102 \mathrm{~cm}(40.2)$ & 23 & 47.9 & 54 & 32.7 & \\
\hline
\end{tabular}

\section{RESULTS}

The study was completed with 500 patients $(213$ M, 287 F). Sixty percent of the subjects were diagnosed with MetS (Table 1). GERD rate was significantly higher in the group with MetS as compared to the group without MetS ( $50.7 \%$ vs $26 \%$ ) (Table $2)$. Women were more likely to have GERD in both groups (MetS, and the control groups, women: 62.6 vs $37 \%$ and men, 28.6 vs $16.7 \%$ ) (Table 3 ). Waist circumferences were found to be higher among female MetS patients with GERD (Table 4). Smok- ing rate was lower in the group with metabolic syndrome. GERD prevalence was found to be higher in nonsmokers. Alcohol consumption rates were similar between subjects with and without GERD. Subjects with GERD were found out to eat larger sized meals. A habit of eating three hours before bedtime was associated with GERD. Physical activity level at work was not correlated with GERD while lesser physical activity during leisure times was significantly correlated with GERD. There was no relation between the type of lying position and GERD (Table 5). 
TABLE 5. Reflux prevalence in groups according to daily habits

\begin{tabular}{|c|c|c|c|c|c|}
\hline & \multicolumn{4}{|c|}{ Reflux } & \multirow{3}{*}{$\mathrm{p}$} \\
\hline & \multicolumn{2}{|c|}{+} & \multicolumn{2}{|c|}{-} & \\
\hline & $\mathrm{n}$ & $\%$ & $\mathrm{n}$ & $\%$ & \\
\hline \multicolumn{6}{|l|}{ Smoking status } \\
\hline Nonsmoker & 123 & 46.4 & 142 & 53.6 & \multirow{4}{*}{$0.045^{*}$} \\
\hline Irregular smoker & 37 & 36.3 & 65 & 63.7 & \\
\hline Former smoker & 25 & 30.9 & 56 & 69.1 & \\
\hline Current smoker & 19 & 36.5 & 33 & 63.5 & \\
\hline \multicolumn{6}{|c|}{ The number of cigarettes smoked daily by current smokers $(n=52)$} \\
\hline$<5$ & 4 & 80.0 & 1 & 20.0 & \multirow{3}{*}{0.098} \\
\hline $5-20$ & 12 & 30.8 & 27 & 69.2 & \\
\hline$>20$ & 3 & 37.5 & 5 & 62.5 & \\
\hline \multicolumn{6}{|l|}{ Alcohol consumption } \\
\hline+ & 5 & 33.3 & 10 & 66.7 & \multirow{2}{*}{0.550} \\
\hline- & 199 & 41.0 & 286 & 59.0 & \\
\hline \multicolumn{6}{|l|}{ The size of meals } \\
\hline Small & 43 & 27.7 & 112 & 72.3 & \multirow{3}{*}{$0.001^{* *}$} \\
\hline Medium & 81 & 41.1 & 116 & 58.9 & \\
\hline Large & 80 & 54.1 & 68 & 45.9 & \\
\hline \multicolumn{6}{|c|}{ Eating 3 hours before bedtime } \\
\hline Never & 34 & 23.6 & 110 & 76.4 & \multirow{4}{*}{$0.001^{* *}$} \\
\hline Rare & 99 & 40.2 & 147 & 59.8 & \\
\hline Often & 56 & 59.6 & 38 & 40.4 & \\
\hline Very often & 15 & 93.8 & 1 & 6.3 & \\
\hline \multicolumn{6}{|c|}{ Physical activity at work } \\
\hline Minimal & 64 & 41,8 & 89 & 58.2 & \multirow{3}{*}{0.086} \\
\hline Average & 108 & 44.1 & 137 & 55.9 & \\
\hline Heavy & 32 & 31.4 & 70 & 68.6 & \\
\hline \multicolumn{6}{|c|}{ Physical activity at leisure time } \\
\hline Minimal & 128 & 56.6 & 98 & 43.4 & \multirow{3}{*}{$0.001^{* *}$} \\
\hline Average & 67 & 32.1 & 142 & 67.9 & \\
\hline Heavy & 9 & 13.8 & 56 & 86.2 & \\
\hline \multicolumn{6}{|l|}{ Sleeping position } \\
\hline Right side & 130 & 43.0 & 172 & 57 & \multirow{4}{*}{0.542} \\
\hline Left side & 47 & 39.5 & 72 & 60.5 & \\
\hline Supine position & 12 & 34.3 & 23 & 65.7 & \\
\hline Prone position & 15 & 34.1 & 29 & 65.9 & \\
\hline
\end{tabular}

\section{DISCUSSION}

This study showed that waist circumference is the most important factor for GERD in female patients with MetS. It is well documented that obesity increases the risk of GERD $[5,6]$. With the growing interest in MetS similar recent studies were performed on coexistence between GERD and MetS [1]. In a 
study conducted with 2457 people in Korea, abdominal obesity was found as a more important factor in the development of erosive gastritis than body mass index [7]. In another study, metabolic syndrome and increased insulin resistance were found to increase the risk of development of erosive esophagitis [8].

Visceral obesity increases intragastric pressure and leads to reflux esophagitis. Visceral fat is metabolically active and it has been associated with low serum levels of protective cytokines, such as adiponectin, and high levels of inflammatory cytokines, such as tumor necrosis factor (TNF)- $\alpha$, interleukin (IL) $-1 \beta$ and IL-6 $[9,10]$.

In the present study, GERD prevalence was found to be higher in women in contrast to the prevalence rates reported for a Japanese cohort [1].

In a large cross-sectional study on abdominal obesity, GERD symptoms and ethnicity of 80110 members of a health organization were investigated. It was found that increased abdominal circumference adjusted for BMI, was an independent risk factor for reflux symptoms (OR, 1.85; 95\% CI, 1.552.21 ) in the white population but not among blacks and Asians which was not influenced by gender [11]. Higher GERD prevalence in Turkish women with MetS in the present study as compared to Japanese women [12] can be related to higher waist circumference of the former group.

Cigarette smoking and alcohol consumption are well known risk factors for GERD [13-16].

We did not find a correlation with smoking or alcohol consumption and GERD, possibly because of higher nonsmoking rate in subjects with metabolic syndrome and very limited alcohol consumption in our population.

Although eating larger-sized meals and eating especially three hours before bedtime were associated with GERD in accordance with the results of other studies [10], we haven't observed any correlation between GERD and physical activity level at work and observed a negative correlation between GERD, and the intensity of leisure time activity. Accumulating information about GERD indicates that GERD coexists with vigorous rather than moderate exercise $[17,18]$. Since gastric fullness in- creases the possibility of GERD [19], leisure time is more convenient for exercises. Investigating sleeping position, any of lying position did not show association with GERD.

Present study is based on a questionnaire survey. An endoscopic evaluation of the study population would be more enlightening.

Conclusion: GERD is present approximately in every one of the two patients with MetS. Every patient who have MetS should be evaluated in terms of GERD symptoms.

Conflict of Interest: No conflict of interest was declared by the authors.

Financial Disclosure: The authors declared that this study has received no financial support.

\section{REFERENCES}

1. Moki F, Kusano M, Mizuide M, Shimoyama Y, Kawamura O, Takagi $\mathrm{H}$, et al. Association between reflux oesophagitis and features of the metabolic syndrome in Japan. Aliment Pharmacol Ther 2007;26:1069-75. CrossRef

2. Vaira D, Gatta L, Ricci C, Castelli V, Fiorini G, Kajo E, et al. Gastroesophageal reflux disease and Barrett's esophagus. Intern Emerg Med 2011;6:299-306. CrossRef

3. Heidelbaugh JJ, Gill AS, Van Harrison R, Nostrant TT. Atypical presentations of gastroesophageal reflux disease. Am Fam Physician 2008;78:483-8.

4. Alberti KG, Zimmet P, Shaw J. Metabolic syndrome--a new world-wide definition. A Consensus Statement from the International Diabetes Federation. Diabet Med 2006;23:469-80. CrossRef

5. Anand G, Katz PO. Gastroesophageal reflux disease and obesity. Gastroenterol Clin North Am 2010;39:39-46. CrossRef

6. Hampel H, Abraham NS, El-Serag HB. Meta-analysis: obesity and the risk for gastroesophageal reflux disease and its complications. Ann Intern Med 2005;143:199-211. CrossRef

7. Kang MS, Park DI, Oh SY, Yoo TW, Ryu SH, Park JH, et al. Abdominal obesity is an independent risk factor for erosive esophagitis in a Korean population. J Gastroenterol Hepatol 2007;22:1656-61. CrossRef

8. Park JH, Park DI, Kim HJ, Cho YK, Sohn CI, Jeon WK, et al. Metabolic syndrome is associated with erosive esophagitis. World J Gastroenterol 2008;14:5442-7. CrossRef

9. Cnop M, Landchild MJ, Vidal J, Havel PJ, Knowles NG, Carr $\mathrm{DR}$, et al. The concurrent accumulation of intra-abdominal and subcutaneous fat explains the association between insulin resistance and plasma leptin concentrations: distinct metabolic effects of two fat compartments. Diabetes 2002;51:1005-15. CrossRef

10. Festi D, Scaioli E, Baldi F, Vestito A, Pasqui F, Di Biase AR, et al. 
Body weight, lifestyle, dietary habits and gastroesophageal reflux disease. World J Gastroenterol 2009;15:1690-701. CrossRef

11. Corley DA, Kubo A, Zhao W. Abdominal obesity, ethnicity and gastro-oesophageal reflux symptoms. Gut 2007;56:756-62. CrossRef

12. Kozan O, Oguz A, Abaci A, Erol C, Ongen Z, Temizhan A, et al. Prevalence of the metabolic syndrome among Turkish adults. Eur J Clin Nutr 2007;61:548-53.

13. Dennish GW, Castell DO. Inhibitory effect of smoking on the lower esophageal sphincter. N Engl J Med 1971;284:1136-7.

14. Dua K, Bardan E, Ren J, Sui Z, Shaker R. Effect of chronic and acute cigarette smoking on the pharyngoglottal closure reflex. Gut 2002;51:771-5. CrossRef

15. Mohammed I, Nightingale P, Trudgill NJ. Risk factors for gastro-oesophageal reflux disease symptoms: a community study.
Aliment Pharmacol Ther 2005;21:821-7. CrossRef

16. Wang JH, Luo JY, Dong L, Gong J, Tong M. Epidemiology of gastroesophageal reflux disease: a general population-based study in Xi'an of Northwest China. World J Gastroenterol 2004;10:1647-51.

17. Schoeman MN, Tippett MD, Akkermans LM, Dent J, Holloway RH. Mechanisms of gastroesophageal reflux in ambulant healthy human subjects. Gastroenterology 1995;108:83-91. CrossRef

18. Clark CS, Kraus BB, Sinclair J, Castell DO. Gastroesophageal reflux induced by exercise in healthy volunteers. JAMA 1989;261:3599-601. CrossRef

19. Emerenziani S, Zhang X, Blondeau K, Silny J, Tack J, Janssens $J$, et al. Gastric fullness, physical activity, and proximal extent of gastroesophageal reflux. Am J Gastroenterol 2005;100:1251-6. 